\title{
ARTICLE
}

\section{Psychopharmacology in children with intellectual disability}

\section{David Bramble}

David Bramble is one of a growing number of child psychiatrists who specialise entirely in the mental health of children with intellectual disability and presently works in a multidisciplinary team in Shropshire. He has had a long-standing interest in autism, psychopharmacology and prescribing practices, particularly in respect of the management of attention-deficit hyperactivity disorder and common sleep disorders, and has lectured and published widely on these and related areas

Correspondence Dr David Bramble, Services for Children and Young People, Telford \& Wrekin Primary Care Trust, Monkmoor

Campus, Woodcote Way,

Shrewsbury SY2 5SH, UK. Email: david.bramble@telfordpct.nhs.uk

\begin{abstract}
SUMMARY
Children and adolescents with intellectual disability have high rates of psychiatric morbidity, the most common presentation being behavioural difficulties, especially in the context of autism. This clinical review describes the applicability of the full range of current psychopharmacological agents to the mental health difficulties commonly encountered in clinical practice in this field, with an emphasis on informing the choice of an initial 'best fit' single agent for the various clusters of symptoms and signs presented by individual patients. It is emphasised that the evidence base for most practice parameters in this area is extremely modest and that a high level of caution is recommended when applying this information in everyday practice. The article also discusses some of the specific difficulties and challenges encountered within the field and makes some practical suggestions for good practice.
\end{abstract}

\section{DECLARATION OF INTEREST}

D.B. has received lecture fees from Flynn Pharmaceuticals, Janssen-Cilag and Lilly. He has also been an advisor to several pharmaceutical companies on various educational projects.

Children and adolescents with intellectual disability (commonly referred to as learning disability by the National Health Service (NHS) in the UK) have significantly higher rates of psychiatric morbidity than those without such disabilities (Emerson 2003). Recent major UK health planning documents have emphasised the role of local child and adolescent mental health services (CAMHS) in providing an inclusive service for this patient group, but currently there is neither consistent provision of such services nor any agreed consensus as to how they should be delivered. Consequently, children with intellectual disability who require psychiatric help may present to a variety of health agencies (CAMHS, specialist learning disability teams within generic CAMHS, community or hospital paediatric services, or lifespan psychiatry of learning disability services). It is probably still the case that much psychological morbidity is unrecognised because healthcare professionals hold false assumptions about the link between psychopathology and underlying cognitive deficit; the term 'diagnostic overshadowing' was coined to describe this phenomenon (Reiss 1982).

Little is known about the past use of psychotropic medication to treat the mental health problems of children and adolescents with intellectual disability. However, it is likely that a restricted range, comprising principally tranquillising medication such as the older antipsychotic drugs (e.g. chlorpromazine, haloperidol, thioridazine) and the antihistaminic sedative hypnotic agents trimeprazine tartrate and promethazine hydrochloride, was used to treat a broad range of challenging behaviours (Santosh 1999). More recently, the full range of psychopharmacological agents used within generic CAMHS and paediatric settings is also being used with this patient group. A survey of consultant psychiatrists who were either clinical specialists in child and/or adult intellectual disability or child and adolescent consultants with a special interest in the field confirmed this trend (Bramble 2007). The strongest research evidence in the field is to be found for the use of psychostimulants to treat attention-deficit hyperactivity disorder (ADHD) (Aman 2003) and for antipsychotics in the treatment of oppositional and aggressive behaviours commonly demonstrated by individuals with autism (McKracken 2002). A practical review of the research evidence emerging from this field has been provided recently in a clinical toolkit devised by the Royal College of Psychiatrists for clinicians working in paediatric learning disability services (Bernard 2009). The review undertaken here will examine the applications of the broad classes of psychotropic medication, suggest 'best fit' first-line agents for the more common symptom clusters encountered with young patients with intellectual disability and provide a number of illustrative case vignettes.

\section{Specific classes of agent Antipsychotic drugs}

Outwardly directed aggression and self-injury, particularly in association with autism, are the most common indications for antipsychotics in paediatric intellectual disability. Ideally, prescription should occur only after behaviour modification, environmental manipulation or other 
non-drug approaches prove to be either ineffective or not applicable in a given case (Benson 2008). The newer, atypical antipsychotics (e.g. risperidone, olanzapine, aripiprazole) are now most commonly prescribed. Low-dose risperidone $\left(\mathrm{a}_{2}\right.$ and $5-\mathrm{HT}_{2}$ receptor blocker) is established as the first-line agent for this purpose (Pandina 2006), and it is licenced for use in the USA for young people with autism (US Food and Drug Administration 2006), but its use in the UK remains off-licence.

Not infrequently, low-dose antipsychotic medication may benefit patients with refractory ADHD symptoms, particularly those who are also exhibiting dangerous levels of aggression (Box 1).

Psychoses (schizophrenia and bipolar disorder) are infrequently encountered in young patients with intellectual disability but may be treated with standard agents and regimens (Armenteros 1997; British Medical Association 2009).

Factors commonly encountered in this group, including physical inactivity, dietary problems and innate predisposition (e.g. Prader-Willi and Down syndromes), often combine to make people with intellectual disability particularly prone to obesity. Given this, serial monitoring of growth indices is recommended, with a strong emphasis placed on diet and exercise when using antipsychotics.

Other important side-effects include those that affect neurological function (extrapyramidal sideeffects), cardiac function $\left(\mathrm{QT}_{\mathrm{C}}\right.$ prolongation and arrhythmias), neuroendocrine effects (hyperprolactinaemia), glucose and lipid metabolism (diabetes and hyperlipidaemias). Patients should be reviewed regularly and remedial measures taken as indicated. Currently, the only mandatory laboratory monitoring (regular white cell counts to detect treatment-induced neutropenia) relates to the use of clozapine, an agent that is very rarely used in child and adolescent intellectual disability practice, being restricted to second-line treatment of refractory schizophrenia.

\section{Dosages}

Taking risperidone as the exemplar, very low doses are used initially $(0.25-0.5 \mathrm{mg})$, once or twice a day, when aggressive, oppositional behaviour and irritability are causing most concern. Doses should be scheduled to calm the patient without causing oversedation. Higher doses may be required (1-2 mg/day up to $8 \mathrm{mg} /$ day) for psychotic disorders. Liquid and dispersible gel formulations are also available.

\section{Psychostimulants}

The cardinal features of ADHD are more prevalent in children with intellectual disability than in
BOX 1 Case vignette: risperidone for refractory aggression
Ryan was a large, 15-year-old boy with profound intellectual disability and refractory aggressive behavioural problems that included lashing out at family, staff and peers and also head-banging. This behaviour represented a slowly emerging puberty-related exacerbation of an earlier habitual pattern that hitherto had been managed effectively with advice and support from behavioural therapists. His unsupported, single-parent mother feared for both her own safety and that of her younger daughter. Staff at Ryan's special school and respite care facility had recently been seriously assaulted. No physical factors could be identified to account for this change in behaviour and there were no symptoms of an underlying serious major mental illness. After a full clinical review and an emergency multi-agency planning meeting that resulted in a decision to pursue increase immediately interim respite care and home-based support, treatment with risperidone liquid commenced starting at $0.25 \mathrm{ml}(0.25 \mathrm{mg})$ twice daily. This was slowly titrated up to $1.0 \mathrm{ml} / \mathrm{mg}$ twice daily over a month, resulting in a significant reduction in recorded aggressive behaviour and self-injury rated as suprathresholddefined 'incidents'. Six months later, Ryan was placed in a residential autism specialist school. He settled quickly and risperidone was slowly $(0.5 \mathrm{ml} / \mathrm{day} / \mathrm{month})$ and successfully withdrawn. a full-time residential placement and to

normally developing children, but psychostimulant treatment can be an effective treatment (Pearson 2004). As in ordinary educational settings, accurate assessment of handicapping symptoms is achieved by obtaining collateral reports from school staff and through direct observation of the patient both at home and at school. When assessing students with intellectual disability in special school settings, it is helpful to ask experienced key staff whether the child is conspicuously physically overactive, inattentive and impulsive given his or her age and ability, compared with their experience of similarly disabled peers. Standard rating scales that provide age and gender normative scores, such as the Conners' scale (Conners 1997), can be helpful, but they have not been standardised in populations with intellectual disability. Assessment of the patient's approximate developmental age provides a comparative level.

The first-line psychopharmacological treatment for severe and psychosocial treatment-resistant ADHD should be methylphenidate, as is the case for normally developing children (National Collaborating Centre for Mental Health 2008); however, in practice, several caveats need to be applied.

First, clinical opinion regarding this treatment in children with intellectual disability and comorbid autism would suggest that they tend to be more sensitive to its mood lability and anxiogenic properties (Erickson 2007), although this assertion is still open to debate (Santosh 2006). Given this, the use of lower initial 'test' doses and slower incremental increases with the short-acting forms of methylphenidate or dexamfetamine is recommended. 
Second, appetite suppression can pose additional difficulties, particularly when stimulants are used with children demonstrating established feeding difficulties (e.g. highly restricted diets encountered in many people with autism); in these circumstances, close attention should be paid to drug scheduling and dietary advice.

Third, difficulties with swallowing and other sensory or muscular factors may restrict the use of slow-release formulations. However, standard tablets may be crushed and stirred into yogurt or jam, capsules may be opened and the contents sprinkled over food and it is possible to obtain liquid methylphenidate on a 'named-patient' basis. Most recently, methylphenidate-impregnated skin patches have become available.

Last, as the overall efficacy and tolerability of stimulants may be lower in some children with certain types of intellectual disability, alternative medication such as atomoxetine or clonidine hydrochloride may be required more commonly than in general paediatric practice (Arnold 2006).

Dosage schedule for methylphenidate

Treatment should begin with a test dose of $2.5-5 \mathrm{mg}$. This is increased usually to a threetimes-a-day dosage regimen; occasionally four times a day is warranted. The usually effective total daily dose is $1-1.5 \mathrm{mg} / \mathrm{kg} /$ day, but higher doses may be required depending on response. Larger single doses may be required in the mornings or at lunchtime, depending on the pattern of symptoms a patient is presenting across the day. Detailed reports of performance over a typical school day greatly inform 'fine-tuning' of doses.

\section{Antidepressants and anxiolytics}

The inherent difficulties involved in accessing direct information about the inner states of children with intellectual disability are probably most evident when evaluating affective symptoms. Towards the lower end of the ability or age scale, observation and inference from third-party reports of changed behavioural or normal habitual biological patterns (e.g. feeding, sleeping) may be the only means of obtaining such information. Overwhelming anxiety, either situational or generalised forms, is the most common presentation and is most often encountered in autism; however, even this most pervasive state may be difficult to detect because of the individual's verbal and non-verbal communication impairments. Pre-existing generalised anxiety, phobia, panics, severe obsessional and ritualistic behaviour can escalate in late childhood, especially as puberty begins, and thereby contribute considerably to the overall handicap and the burden of care for families and other caregivers.

Initial management requires that any probable contributory environmental factors that may have either triggered or are maintaining the symptoms (e.g. family crises, change of school) are addressed. However, when symptoms are severe and enduring, selective serotonin reuptake inhibitors (SSRIs) such as fluoxetine hydrochloride and citalopram can be extremely beneficial, although the evidence base for their use in practice is currently poor. If it is decided to try a serotonergic drug, it is worth working through a number, including clomipramine. Common side-effects include mild gastrointestinal disturbance, sleep difficulties and agitation, but these are generally transient. Less commonly, activation symptoms may occur within the first week or so of treatment.

Obsessional and compulsive symptoms, as well as those incorporated into autistic stereotypies, may also be alleviated by SSRIs, albeit using higher doses than with uncomplicated depression. In treatment-resistant cases, other serotonergic antidepressant agents such as clomipramine may be effective (Garber 1992).

For the management of overwhelming transient anxiety linked to predictably distressing events such as visits to hospital, start of the school term, aeroplane flights and bonfire nights, small tactical doses of benzodiazepines (lorazepam 1-2 mg or diazepam $2-5 \mathrm{mg}$ ) can be deployed to good effect. However, their well-recognised potential for producing occasional paradoxical disinhibition must be explored beforehand, with a test dose given at a convenient opportunity. Where physiological symptoms of anxiety are prominent in these circumstances, a $\beta$-blocker such as propranolol (20-100 mg) may be given half an hour before a predictably distressing event.

As is the case for patients with major depressive disorder, children with pubertal exacerbation of anxiety-related symptoms may require long-term treatment with SSRIs. Treatment with benzodiazepines may also be employed in this manner, but with added caution given the risks of developing tolerance and also the effects on seizure threshold following rapid withdrawal. In clear cases of unipolar depression (major depressive disorder), standard doses of antidepressant drugs may be used, but the threshold for prescription may be influenced by the individual's capacity to respond to first-line psychological measures.

The efficacy of other SSRIs or other classes of antidepressant medication has not been studied systematically, but substitution of another SSRI for fluoxetine is a common practice; however, specific 
agents such as citalopram have not been shown to be effective in children who have comorbid autism (King 2009).

Symptoms of a discontinuation syndrome on abrupt drug withdrawal may be misinterpreted as recurrence of the depressive symptoms. Discontinuation symptoms may be encountered more frequently in SSRIs with a short elimination halflife.

Antipsychotics may be prescribed in addition to antidepressants in cases of psychotic depression and may also be prescribed in low dosage for patients with treatment-refractory anxiety, especially in the context of autism. The uses of other anxiolytic agents have not been evaluated systematically, but short-term use of buspirone may yield benefits when others fail (Ratey 1991).

\section{Dosage schedule for antidepressants and anxiolytics}

Taking fluoxetine as the exemplar, the initial dose should be low ( $5 \mathrm{mg}$ in smaller children and $10 \mathrm{mg}$ in larger and older children) but may be increased incrementally to the normal 'adult' doses employed for major depression, severe general anxiety and disabling obsessive-compulsive symptoms (20$40 \mathrm{mg}$ /day). Occasionally, doses of $60 \mathrm{mg} /$ day or more may be effective. Fluoxetine syrup is also available at a strength of $2.5 \mathrm{ml} / 10 \mathrm{mg}$. Three to four months would be required for an adequate trial of efficacy.

\section{Anticonvulsants/mood stabilisers}

This class of agent has been used in adult psychiatry for many years for the purpose of emotional stabilisation and thereby behavioural control, particularly for episodic rages in bipolar disorder and behavioural dyscontrol syndromes. Carbamazepine, valproic acid and lamotrigine may also be given to children and adolescents; however, the evidence base for such off-label use is extremely modest and is based on extrapolation from published work with adults and also peer opinion and practice (Bernard 2009). It should be noted that other anticonvulsants such as phenytoin, topiramate and, in particular, vigabatrin do not appear to have these properties and are more likely to produce paradoxical behavioural problems (Besag 2004).

In established bipolar disorder, valproic acid, with or without concurrent use of an antipsychotic such as risperidone, is a standard first-line treatment (Danielyan 2005). The use of lithium carbonate for refractory bipolar disorder in paediatric patients with intellectual disability has not been established but, provided that the normal cautions apply (maintaining a safe drug level, fluid and electrolyte balance and monitoring thyroid function), there is no compelling evidence that it should not be used. However, the requirement for regular blood tests may render this option unviable for some patients.

\section{Dosages for anticonvulsants/mood stabilisers}

These are the same as those employed for seizure control and the same cautions and monitoring arrangements apply. Slow titration and a 3- to 4 -month trial is recommended. However, for patients with longer mood-change cycles, a proportionately longer trial would be necessary.

\section{Sedative-hypnotics and related agents}

The majority of the common sleep problems encountered among children and adolescents with intellectual disability are largely behavioural in nature (night-settling, night-waking and early waking problems), although a minority are directly related to the underlying nature of the handicap or medical or psychiatric conditions associated with it. Previously, antihistamines were regarded as a mainstay of treatment, but subsequent research conducted with normally developing children has demonstrated that these agents afford, at best, only temporary relief (Ramchandani 2000). Furthermore, antihistamines may also be prone to produce paradoxical reactions in a minority of children (Simonoff 1987); rarely, they may produce acute dystonias and other extrapyramidal sideeffects, although owing to the heterogeneous nature of the group, reactions are extremely variable.

Currently, behavioural approaches based on the principles of establishing an effective sleep routine and promoting habits that facilitate sleep onset (good sleep hygiene), reducing the reinforcing elements (e.g. inappropriate parental attention) and a system of developmentally appropriate rewards together constitute the initial treatment of choice and are associated with good general outcome.

Sedative agents are best reserved for refractory cases or for crisis; the principal agent, particularly for patients with autism, is melatonin, which appears to be both effective and well tolerated (Turk 2003). With teenage and more able patients who experience temporary insomnia in response to a particular stress or trauma, a short course of temazepam or one of the 'z-drugs' (zolpidem, zopiclone or zaleplon) may be used when other measures fail.

Benzodiazepine hypnotics are contraindicated for patients with obstructive sleep apnoea or morbid obesity because of the high risk of respiratory arrest through smooth muscle relaxation and airway collapse. 
BOX 2 Case vignette: melatonin and sleep hygiene for sleep problems
At presentation, Ahmed was 7 years old, had severe autism and an 10 of 57 . For several years he demonstrated difficulties settling at night and staying in his bed during the night, when he would wander into his parents' bed and his father would have to leave the bed. A prescription for an antihistamine sedative reportedly 'only made him worse'. Two weeks of sleep diary data revealed a marked variation in settling time but a more regular pattern of waking after a couple of hours of sleep and making his way into his parents' bed. He was predictably difficult to manage in the mornings and would sometimes fall asleep at school in the afternoon. Treatment involved the elaboration and implementation of a regular sleep routine with attention to strict sleep hygiene. His parents were advised not to allow him into their bed but to firmly and silently guide him back to his own bed. This yielded positive results after only a few days in terms of his night-waking pattern, but he continued to take up to 3 hours to settle each night. Melatonin was prescribed at a dose of $4 \mathrm{mg}$ at night to good effect; however, subsequent regular attempts to withdraw the drug were unsuccessful and, 3 years on, he still requires it.
Sedative-hypnotics do not have a proven role in children who wake habitually throughout the night or those who wake early; behavioural modification measures are best applied in these circumstances.

\section{Doses for sedative-hypnotics and related agents}

Melatonin is usually prescribed at a dose range of $0.5-15 \mathrm{mg}$ at night. It is recommended that its unlicensed status is discussed with parents and carers. Repeat prescriptions are usually provided by a specialist clinician because most general practitioners are not prepared to do so (Bramble 2005). Periodic, planned trials of withdrawal of the agent should be incorporated into the care plans of all patients taking melatonin or any other sedative-hypnotic on a long-term basis; however, reemergence of the original night-settling difficulties is not uncommon (Box 2).

The addition of a small dose of the $\alpha$-adrenergic blocking agent acebutolol $(10 \mathrm{mg} / \mathrm{kg})$ in the morning has been shown in small open trials to inhibit the inappropriate endogenous melatonin secretion in the circadian rhythm seen in patients with Smith-Magenis syndrome (De Leersnyder 2001). The $\alpha$-adrenergic agonist clonidine (50-125 $\mu \mathrm{g}$ at night) may be helpful in patients who fail to respond to melatonin and where other measures have failed, especially in patients with comorbid ADHD (Ingrassia 2005). In all cases, attention to the non-pharmacological management should continue in parallel to drug treatment.

\section{Other useful agents}

Significant symptoms of mental distress may be induced in children with intellectual disability by physical illness or injury. Owing to common problems such as communication difficulties, social impairments and sensory problems (e.g. an extremely high pain threshold not uncommonly encountered in some children with autism), patients may be constitutionally unable to demonstrate or complain of characteristic pain and discomfort associated with physical symptoms. In such circumstances, the discomfort from constipation, earache, dental pain, hay fever or sinusitis, for example, may be manifested as self-injurious behaviour such as severe head-banging and misconstrued as an acute mental health problem (Box 3).

In young women with autism, pain and discomfort commonly associated with the premenstrual period may manifest as cyclical increased irritability and either outwardly aggressive or self-injurious behaviour. Regular pain control during this period (e.g. paracetamol $1 \mathrm{~g}$ four times a day) may either reduce or totally ameliorate such difficulties. Painful, irregular and heavy periods may be eased and regularised with either the contraceptive pill or an injectable alternative.

Last, common conditions that afflict the ears (wax, foreign bodies), nose (rhinitis, mucus congestion, foreign bodies), eyes (conjunctivitis, styes), upper respiratory tract and air passages (chronic sinusitis) may all present with emotional and behavioural disturbance, but will usually resolve with simple remedial measures. Close collaboration with primary care colleagues is most helpful in these circumstances.

\section{Special issues}

\section{Psychopharmacological polypharmacy}

Monotherapy seems to be the norm in the prescribing practices of psychiatrists specialising in child intellectual disability (Bramble 2007). However, it is not unusual to encounter young patients, particularly those in the care of Social

\section{BOX 3 Case vignette: physical discomfort presenting as depression}

Stuart ( 15 years old with Down syndrome and an 10 of 32) was observed by both his mother and his teacher to have become withdrawn, tearful and to have lost his robust appetite following a viral chest infection a month previously. His general practitioner suspected depression. The history revealed that Stuart had not had a normal bowel movement since his illness.

On physical examination he appeared to be dehydrated and his abdomen was distended and tender to deep palpation. Rectal investigation revealed a faecally loaded rectum and some watery diarrhoea. Treatment with an enema followed by a month's course of an osmotic laxative rapidly restored Stuart's previous euthymia. 
Services (the 'looked-after' system), who have been prescribed various combinations of psychotropic drugs, often by several clinicians, over a long period. Another complicating factor is that, owing to high rates of physical comorbidity, patients with intellectual disability may be taking other medications with either psychotropic actions of their own or interactions with psychotropic agents. However, in some specific circumstances certain combinations may be both necessary and also highly effective (Box 4).

\section{Long-term treatment and trial of withdrawal}

Some patients, particularly those who are older, with severe intellectual disability and comorbid ADHD and autism, may require long-term drug treatment, but a planned withdrawal of medication needs to be considered at every review of the patient. Such a trial needs to be conducted at a time when any potential re-emergence of underlying disabling symptoms is likely to cause least disruption for the child, family and the school. Length of withdrawal depends on the type of drug under consideration. For example, in the case of short-acting agents that carry a low risk of withdrawal syndromes (such as methylphenidate or melatonin), a few days of total omission will probably reveal the need for continuation. Alternatively, drugs such as risperidone, prescribed in modest doses (1-3 mg/ day) and taken over a long period, need to be withdrawn very slowly, often over several weeks, in order to avoid the emergence of subjectively unpleasant withdrawal dyskinesias.

Patients should be reviewed more regularly over any period of planned withdrawal so that reemergence of target symptoms or behaviours can be addressed quickly.

\section{Emergency or rapid sedation}

There are several specific situations where the prescription of rapid or emergency sedation may be necessary. Preparing patients for predictably distressing events such as visits to hospital, to the dentist or for specific investigations (e.g. physiological assessments, blood tests) may simply require increasing the dose of any potentially sedating medication (e.g. risperidone) the patient is already taking. Otherwise, melatonin at a dose of $10 \mathrm{mg}$ is often used before electroencephalography, for example, although sometimes anaesthetic agents such as midazolam ( $1 \mathrm{ml} / 10 \mathrm{mg}), \gamma$-hydroxybutyrate or even ketamine are given by experienced staff in healthcare settings to effect adequate sedation. The National Institute for Health and Clinical Excellence (NICE) is currently consulting on the subject ('Sedation in children and young
BOX 4 Examples of potentially beneficial drug combinations

Methylphenidate and melatonin

This combination may be used to treat refractory night-settling sleep problems commonly encountered in children with ADHD and autism-spectrum disorders.

\section{Risperidone and methylphenidate}

It may be necessary to use risperidone in low dosage to reduce the high arousal and irritability often encountered during puberty in hyperactive patients with autism, which can produce entrenched patterns of externalised aggressive behaviour that does not respond adequately to psychostimulant monotherapy and behavioural management strategies.

\section{Fluoxetine and melatonin}

Patients with depression and/or chronic anxiety, especially those with comorbid autismspectrum disorders, may require the combination of fluoxetine and melatonin if refractory sleep-onset insomnia is prominent.

people'), with an anticipated publication of clinical guidelines in December 2010.

In the case of acutely disturbed behaviour that is not amenable to physical restraint or other management strategies and when oral medication is refused, intramuscular lorazepam and/or haloperidol may be used, although local agreed protocols must be followed.

\section{Special investigations}

If special investigations pose particular difficulties in terms of the patient's cooperation or tolerability, in my view such procedures should be kept to an absolute minimum and reserved for instances where there is a high risk of adverse physiological responses to medication or where there are specific clinical recommendations for an investigation (e.g. monitoring neutrophil counts in clozapinetreated patients). It can be helpful to contact other clinicians involved in a case so that phlebotomy, in particular, can be arranged when a convenient opportunity presents itself, for example when the patient is sedated or even unconscious through a general anaesthetic for elective dental work.

\section{More practical suggestions}

\section{Keeping people informed}

Often, children with intellectual disability may require medication to be administered by a number of individuals other than just their parents: school, nursery, respite care and play-scheme staff. Given this, keeping everyone involved and informed about the patient's current regimen is important. It is also good practice to ensure that those administering the medication know exactly what they are expected to do in these circumstances - misinterpreting a decimal point when administering the small doses of risperidone syrup $(1 \mathrm{mg} / \mathrm{ml})$ can result in acute, and potentially highly dangerous, oversedation. 


\section{Adherence issues}

Many children with severe intellectual disability are incapable of making an informed choice about taking medication; however, every attempt should be made to explain in a developmentally appropriate manner the basic reasons why they are expected to do so and what this will involve. Older and more able patients should be encouraged actively to be involved in the decision-making process and respect should be accorded to their views. Unwin \& Deb (2006) have produced an easy-to-read booklet for adults with intellectual disability that may be used with older and more able paediatric patients.

In all circumstances, parents and, in the case of children within the looked-after system, carers, social workers and guardians, should provide consent to any proposed treatment. They should also be fully apprised of the risks and commonly encountered side-effects and their significance before treatment starts. Where particular problems present in terms of a patient's idiosyncratic refusal or inability to take standard preparations of medication through physical restrictions (e.g. dysphagia, gastrostomy), advice from a hospital pharmacist is often invaluable in these circumstances. For example, liquid versions of most of the regularly employed drugs discussed in this review, including methylphenidate and melatonin, are now available.

\section{Professional networking}

At present, given that there are relatively few child or learning disability psychiatrists who specialise entirely in this field, it is beholden on them to work with their peers as well as obtaining support from their local generic CAMHS and paediatric colleagues. The 100-strong, independent Child and Adolescent Learning Disability Psychiatry Network was established in 2002 and now holds regular national and supra-regional meetings, conducts psychopharmacological audit and research projects, provides a forum to discuss clinical matters and responds to service planning initiatives. In this way, prescribing practices as well as other aspects of clinical management can be effectively 'benchmarked' and described in publications such as this article.

\section{Summary of prescribing strategies}

A scheme intended to allow the more accurate targeting of drugs for the broad symptom clusters presenting in children and adolescents with autism has been suggested by Myers \& Johnson (2007). An adapted version of this scheme that encompasses the wider field of psychiatric practice is presented in Table 1, although it is intended to be used only as a general guide. Clinicians must bear in mind that most of the suggested drug treatments rest on clinical experience and peer opinion rather than robust empirical evidence.

TABLE 1 Targeting medication to symptom clusters

\begin{tabular}{|c|c|c|c|}
\hline Symptom cluster & Probable diagnostic categories & Order of applicable drug class & Examples \\
\hline Aggression, self-harm, explosive temper & $\begin{array}{l}\text { Conduct disorder, intermittent } \\
\text { explosive disorder }\end{array}$ & $\begin{array}{l}\text { 1. Atypical antipsychotic } \\
\text { 2. Anti-epileptic mood stabiliser } \\
\text { 3. } \alpha \text {-adrenergic agonist }\end{array}$ & $\begin{array}{l}\text { Risperidone, olanzapine, aripiprazole } \\
\text { Carbamazepine, valproic acid } \\
\text { Clonidine }\end{array}$ \\
\hline Hyperactivity, impulsivity, inattention & $\begin{array}{l}\text { Attention-deficit hyperactivity } \\
\text { disorder }\end{array}$ & $\begin{array}{l}\text { 1. Stimulant } \\
\text { 2. Noradrenaline reuptake inhibitor } \\
\text { 3. Mood stabiliser } \\
\text { 4. } \alpha \text {-adrenergic agonist } \\
\text { 5. Atypical antipsychotic }\end{array}$ & $\begin{array}{l}\text { Methylphenidate, dexamfetamine } \\
\text { Atomoxetine } \\
\text { Carbamazepine } \\
\text { Clonidine } \\
\text { Risperidone }\end{array}$ \\
\hline Severe anxiety & $\begin{array}{l}\text { Generalised anxiety disorder, } \\
\text { panic disorder, specific phobias }\end{array}$ & $\begin{array}{l}\text { 1. SSRI } \\
\text { 2. Benzodiazepine }\end{array}$ & $\begin{array}{l}\text { Fluoxetine, sertraline } \\
\text { Lorazepam }\end{array}$ \\
\hline $\begin{array}{l}\text { Depressive phenotype (withdrawal, } \\
\text { irritability, sadness, reduced energy, sleep } \\
\text { disturbance, change in appetite, loss of usual } \\
\text { interests or preoccupations) }\end{array}$ & Major depressive disorder & SSRI & Fluoxetine, sertraline \\
\hline Insomnia & Sleep-onset association disorder & $\begin{array}{l}\text { 1. Sedative-hypnotic } \\
\text { 2. } \alpha \text {-adrenergic agonist }\end{array}$ & $\begin{array}{l}\text { Melatonin, 'z-drugs' (zolpidem, } \\
\text { zopiclone, zaleplon) } \\
\text { Clonidine }\end{array}$ \\
\hline $\begin{array}{l}\text { Handicapping obsessions and compulsions, } \\
\text { extremely rigid or ritualistic behaviour }\end{array}$ & $\begin{array}{l}\text { Obsessive-compulsive disorder } \\
\text { Autistic stereotypy }\end{array}$ & $\begin{array}{l}\text { 1. SSRI } \\
\text { 2. Atypical antipsychotic }\end{array}$ & $\begin{array}{l}\text { Fluoxetine, sertraline } \\
\text { Risperidone, olanzapine, aripiprazole }\end{array}$ \\
\hline $\begin{array}{l}\text { Bipolar phenotype (behavioural cycling } \\
\text { associated with rages, aggressiveness, } \\
\text { irritability, self-injury and euphoria; extreme } \\
\text { hyperactivity or restlessness, diminished } \\
\text { need for food or sleep, over-talkative) }\end{array}$ & Bipolar disorder & $\begin{array}{l}\text { 1. Mood stabiliser } \\
\text { 2. Atypical antipsychotic } \\
\text { 3. Lithium salts }\end{array}$ & $\begin{array}{l}\text { Carbamazepine, valproic acid } \\
\text { Risperidone, olanzapine, aripiprazole } \\
\text { Lithium carbonate }\end{array}$ \\
\hline
\end{tabular}

SSRI, selective serotonin reuptake inhibitor. 


\section{Basic principles of prescribing}

Once an agent has been identified that represents the 'best fit' for the individual concerned, the following principles can be applied in most cases.

- Discuss the risks and benefits with the parent or carer, and as far as possible the patient, using developmentally appropriate language or communication aids.

- Assess the patient's capacity to consent to treatment and if this is lacking obtain permission from the patient's next of kin, guardian or social worker in the case of children in care.

- Decide which formulation would best suit the patient and also discuss other options should the medication prove ineffective or partially effective.

- Establish treatment goals, baseline assessments of target symptoms, measure key physiological parameters and issue treatment information materials.

- Explain the time scale of the proposed trial of treatment, schedule and form of reviews and emergency contact arrangements (particularly at the outset when frequent contact is required).

- Disseminate correspondence to all key professionals involved throughout the course of treatment, especially after changes of medication or its dosage.

- Repeat and document ratings of target symptoms, physiological indices and screening for common drug side-effects.

- Allow sufficient time for the medication to work within the usual dosage range before higher doses, augmentation or substitution is considered.

- Consider the use of another class of medication for symptoms unrelated to the current drug therapy's targets that are causing additional difficulties, being mindful of the possibility of drug interaction.

- With any medication that has been used for over a year, consider a trial of phased withdrawal to determine ongoing benefit and need.

(Key points 1.)

\section{Conclusions}

Applying the full range of psychopharmacological agents in this specialist field can often significantly improve the mental health of children with intellectual disability and thus reduce their overall handicap, help to optimise their developmental potential and alleviate the burden of care for affected families. Using the most effective and safest 'best-fit' single agent for the most disabling cluster of symptoms first is to be strongly encouraged. However, the specialist psychiatrist will often

\section{KEY POINTS 1 Learning points}

\begin{tabular}{|ll|}
\hline - Children with intellectual disability & - Efficacy may be lower and side- \\
have high rates of psychiatric & effects more common in certain sub- \\
morbidity & populations, but medication should \\
- Behavioural problems ('challenging & not be withheld for these reasons \\
behaviour') constitute the most & - Routine physical investigations \\
common presentations & should be conducted unless the \\
- Environmental and physical factors & patient manifests extreme distress \\
are often important contributory & - Aim for monotherapy, starting with \\
factors and need to be addressed & low doses with slow increases of \\
before psychotropic medication is & dose and regular review \\
considered & - Currently, the evidence-base for drug \\
- Behavioural management conducted & treatment is strongest for stimulants \\
by skilled practitioners in a & and low-dose antipsychotics, but \\
multidisciplinary learning disability & poor for most other classes of agent \\
CAMHS team may obviate the need & - Cautious, reflective practice \\
for medication & with good peer support is to be \\
- Use 'best fit' agents for symptom & recommended \\
clusters if formal psychiatric & \\
diagnosis is uncertain or not possible & \\
\hline
\end{tabular}

be treating multiple problems with some form of psychotropic medication over several years, having to change the dose or even class of drug against a background of growth, other developmental challenges (particularly in patients with autism during puberty) and both the predictable and nonpredictable stressful events of everyday life.

Given that physical illness is more common in this group, close collaboration with paediatric services is desirable; combined clinics between psychiatrists and paediatricians yield many benefits for patients with complex problems and their families, perhaps the greatest being a reduction in the number of out-patient appointments.

To date, most research in this specialist field comprises case reports, case series, open studies and small randomised controlled trials. Using lower initial doses, with slower increases of dose and closer monitoring compared with practice for normally developing patients, are all probably desirable practices. Further quantitative and qualitative research is required to test the many propositions and assumptions summarised in this article.

\section{References}

Aman M, Buican B, Arnold L (2003) Methylphenidate treatment in children with borderline $\mathrm{IO}$ and mental retardation: analysis of three aggregated studies. Journal of Child and Adolescent Psychopharmacology 13: 27-38.

Armenteros J (1997) Risperidone in adolescents with schizophrenia. Journal of the American Academy of Child and Adolescent Psychiatry 36: 694-700.

Arnold L, Aman M, Cook A (2006) Atomoxetine for hyperactivity in autistic spectrum disorder: a placebo-controlled crossover trial. Journal of the American Academy of Child and Adolescent Psychiatry 45: 1196-205.
MCO answers

1 b $\quad 2$ e $\quad 3$ a $\quad 4$ e $5 c$ 
Benson B, Brooks W (2008) Aggressive challenging behaviour and intellectual disability. Current Opinion in Psychiatry 21: 454-8.

Bernard S, Turk J (eds) (2009) Medical. In Developing Mental Health Services for Children and Adolescents with Learning Disabilities: a Toolkit for Clinicians: 42-8. RCPsych Publications.

Besag F (2004) Behavioural effects of the newer antiepileptic drugs. Expert Opinion on Drug Safety 3: 1-8.

Bramble D, Feehan C (2005) Psychiatrists' use of melatonin with children. Child and Adolescent Mental Health 10: 145-9.

Bramble D (2007) Prescribing practices in British child psychiatrists for children with learning disabilities. Journal of Psychopharmacology 21: 486-91

British Medical Association, Royal Pharmaceutical Society of Great Britain, Royal College of Paediatrics and Child Health, et al (2009) Section 4.2: drugs used in psychosis and related disorders. In British National Formulary for Children (2010-2011). Pharmaceutical Press.

Conners CK (1997) Conners Rating Scales - Revised. Multi-Health Systems.

Danielyan A, Kowatch R (2005) Management options for bipolar disorder in children and adolescents. Paediatric Drugs 7: 277-94.

De Leersnyder $H$, de Blois $M$, Vekemans $M$, et al (2001) Beta (1)-adrenergic antagonists improve sleep and behavioural disturbances in a circadian disorder, Smith-Magenis syndrome. Journal of Medical Genetics 38: 586-90.

Emerson E (2003) Prevalence of psychiatric disorders in children and adolescents with and without intellectual disability. Journal of Intellectual Disability Research 47: 51-8.

Erickson C, Posey D, Stigler K, et al (2007) Pharmacologic treatment of autism and related disorders. Pediatric Annals 36: 575-85.

Garber H (1992) Clomipramine treatment of stereotypic behaviors and self-injury in patients with developmental disabilities. Journal of the American Academy of Child and Adolescent Psychiatry 31: 1157-60.

Ingrassia A, Turk J (2005) The use of clonidine for severe and intractable sleep problems in children with neurodevelopmental disorders: a case series. European Child and Adolescent Psychiatry 14: 34-40.

King B, Hollander E, Sikich L, et al (2009) Lack of efficacy of citalopram in children with autism spectrum disorders and high levels of repetitive behavior: citalopram ineffective in children with autism. Archives of General Psychiatry 66: 583-90.

McCracken J, McGough J, Shah B, et al (2002) Risperidone in children with autism and serious behavioural problems. New England Journal of Medicine 347: 314-21.
Myers S, Johnson C (2007) Management of children with autism spectrum disorders. Pediatrics 120: 1162-82.

National Collaborating Centre for Mental Health (2008) Attention Deficit Hyperactivity Disorder. The NICE Guideline on Diagnosis and Management of ADHD in Children, Young People and Adults. British Psychological Society, Royal College of Psychiatrists (http://www.nice. org.uk/nicemedia/live/12061/42060/42060.pdf).

Pandina G, Aman M, Findling R (2006) Risperidone in the management of disruptive behaviour disorders. Journal of Child and Adolescent Psychopharmacology 16: 379-92.

Pearson D, Lane D, Santos C, et al (2004) Effects of methylphenidate treatment in children with mental retardation and ADHD: individua variation in medication response. Journal of the American Academy of Child and Adolescent Psychiatry 43: 686-98

Ramchandani P, Wiggs L, Webb V, et al (2000) A systematic review of settling and night waking problems in children. BMJ 520: 209-13.

Ratey J, Sovner R, Parks J, et al (1991) Buspirone treatment of aggression and anxiety in mentally retarded patients: a multiple-baseline, placebo lead-in study. Journal of Clinical Psychiatry 52: 159-62.

Reiss S, Levitan G, Szysko J (1982) Emotional disturbance and mental retardation: Diagnostic overshadowing. American Journal of Mental Deficiency 86: 567-74.

Santosh P, Baird G (1999) Psychopharmacology in children and adults with intellectual disability. Lancet 354: 233-43.

Santosh P, Baird G, Pityaratstian N, et al (2006) Impact of comorbid autism spectrum disorders on stimulant response in children with attention deficit hyperactivity disorder: a retrospective and prospective effectiveness study. Child: Care, Health and Development 32: 575-83.

Simonoff E, Stores G (1987) Controlled trial of trimeprazine tartrate for night waking. Archives of Diseases of Childhood 62: 253-7.

Turk J (2003) Melatonin supplementation for severe and intractable sleep disturbance in young people with developmental disabilities: short review and commentary. Journal of Medical Genetics 40: 793-6.

Unwin G, Deb S (2006) Your Guide to Taking Medicine for Behaviour Problems: Easy Read. University of Birmingham (http://www.ldmedication.bham.ac.uk/2erg.pdf). Also available in audio format as an MP3 download.

US Food and Drug Administration (2006) FDA approves the first drug to treat irritability associated with autism, risperidal. FDA /http //www fda gov/NewsEvents/Newsroom/PressAnnouncements/2006/ucm108759.

\section{MCOs}

Select the single best option for each question stem

1 Antipsychotic medication for behavioural problems in paediatric intellectual disability:

$\mathrm{a}$ is a first-line treatment

b may benefit ADHD symptoms

c is often ineffective in low doses

d may not be used with other agents

e has been shown to produce lasting beneficial effects.

2 Selective serotonin reuptake inhibitors:

a are poorly tolerated

b should not be used in patients with autism

c are a standard treatment for situational anxiety

d may be given only for short periods

e may reduce autistic preoccupations and stereotypical behaviours.
3 With regard to the prescription of sedative-hypnotics and melatonin to young people with intellectual disability and common sleep problems:

a clonidine may be used in refractory cases

b melatonin is a first-line treatment

c paradoxical reactions are extremely common

$\mathrm{d}$ benzodiazepine drugs are indicated for patients with obstructive sleep apnoea

e these should not be withdrawn periodically.

\section{Stimulant medication:}

$\mathrm{a}$ is normally the only treatment required for patients with intellectual disability and ADHD

b should be used for appetite suppression

c is not tolerated by children with autism

d should only be used in low doses

$\mathrm{e}$ is often effective in patients with both ADHD and autism.
5 A general principle regarding medication in children with intellectual disability is that:

a most are likely to develop adverse reactions to drug treatments

b polypharmacy is usually indicated

c initial dosage regimens should be different from those for normally developing patients

$d$ the underlying evidence-base for medication is strong

e medication is an acceptable substitute for comprehensive care. 